\title{
O Vídeo Educativo Produzido pelo Núcleo de Tecnologia Educacional para a Saúde/UFRJ: uma Visão Crítica
}

\begin{abstract}
RETUMO
A partir da recunstruça histórica da produça de videos cducativos no Nules/CCS/NFR/ c de sua articulacto rom diferentes correntes educacionais e com o contcxto sócioeconómico maior; busca-se un entendirnento das idcologias sumjacentes ao trabalho do núcleo ao kmyo de seus 20 anos de existincia.
\end{abstract}

\section{INTRODUÇÃO}

A produçào de videos tem ocupado um lugar privilegiado no trabalho do Núcleo die Tecnologia Educacional para a Saúde (Nutes) desde a sua criação, $\mathrm{cm} \mathrm{1972,} \mathrm{a} \mathrm{té} \mathrm{o} \mathrm{presente} \mathrm{momento.} \mathrm{À} \mathrm{medida}$ que se analisa essa produção, levando em conta elementos de sua forma e contcúdo, desvenda-se a dinàmica que historicamente tem caracterizado o papel do núcleo na educação brasileira. O presente trabalho está referenciado pelos relatórios anuais do Nutes e por entrevistas de docentes e técnicos que, ao longo dos anos, vèn influindo nos rumos que toma o trabalho desse núcleo.

\section{NUTES: CRIAÇÃO E OS PRIMEIROS DEZ ANOS}

Em 1972, o Instituto de Biofísica da Universidade Federal do Rio de Janeiro (UFRJ) apresentou projeto ao Ministério do Planejamento (lpea), solicitando recursos para a aplicação de tecnologia educacional visando à melhoria do Ensino de Biofísica e Fisiologia dessa instituiçāo. O interesse imediatamente expresso por outras unidades do Centro de Ciências da Saúde (CCS)/UFRJ na melhoria do ensino das ciéncias da saúde resultou na expansāo da abrangéncia do projeto. Assim, em julho de 1972, acrescentou-se um novo órgáu de caráter suplementar ao Centro de Ciências da Saúde (CCS): o Núcleo de Tecnologia Educacional para a Saúde (Nutes).

1 Professora Adfanta. Nuicleo de Ternologia Educociumal para a Saúde (Nuiles), Centro des Cirncios da Saúde. Untreersidade ficherel do Riun dr funciro. 
A Organizaçāo Pan-Americana da Saúde (OPS), reconhecendo a importância do projeto, assinou um acordo com o governo brasileiro, representado pela UFRJ e os ministérios do Planejamento e da Saúde, estabelecendo, em setembro de 1972, o Centro Latino-Americano de Tecnologia Educacional para a Saúde (Clates), sediado no Nutes, com o objetivo de viabilizar a difusāo das tecnologias criadas para a América Latina.

Os objetivos traçados para o Nutes/Clates, quando de sua criaçāo, referem-se principalmente a: "preparo pedagógico e adestramento no uso de novos materiais instrucionais, inclusive o computador, (...) organizar cursos em instruçāo programada e preparar programas instrucionais audiovisuais, (...) delinear projetos de cursos de Ciências Biomédicas visando à individualizaçāo do processo educacional" ${ }^{\prime 5}$ e à prestação de assessoria pedagógica no planejamento de cursos. Sua equipe foi formada por pessoal das áreas de Saúde, Psicologia, Educaçāo, Sociologia, Computaçāo, Biblioteconomia e por profissionais da área de produçāo de audiovisuais.

Conforme lembrado por Sigaud ${ }^{\mathbf{B}}$, no início de sua existência, o trabalho do Nutes voltou-se essencialmente para o atendimento das necessidades relativas aos cursos das diferentes unidades do CCS. Assim, dedica-se a atividades como a elaboraçāo de projetos de cursos de Ciências Biomédicas, visando à individualização do processo educacional e ao desenvolvimento de programas (softwares) que possibilitem o emprego de computador no ensino das Ciências Biomédicas. A partir de 1973, passa a prestar assessoria numa reforma curricular que se inicianesse mesmo ano, tendo em vista integrar as disciplinas do ciclo básico do Centro de Ciências da Saúde (Anatomia, Físiologia, Histologia, etc.) em blocos sistêmicos (sistema nervoso, ca rdiorrespiratório, endócrino, etc.) segundo o modelo clássico da Western Reserve University. Os videos eram elaborados como parte da assessoria dacta aos cursos, servindo como instrumentos para ilustrar as aulas. Desta forma, em 1976, quando o Nutes completa a instalação do setor de produçāo audiovisual, produz uma séric de videos para serem traballhados no ciclo básico. Explorava-sc, desse modo, o potencial desse recurso de usar cores e movimentos para aumentar a eficiência do ensino. Além disso, os videos focalizavam habilidades importantes para o profissional de saúde, tais como a aplicaçăo de uma injeçāo intradérmica, a arrumaçāo do leito e a tomada de pressāo arterial.

Data de 1976 a instalaçāo de sistema de circuito fechado de TV em cores no Centro de Ciências da Saúde, permitindo a projeçāo de material audiovisual em salas de aula e em cabinas na biblioteca. A partir dai, os programas passaram a ser requisitados por um sistema de telefone interno, que ligava os lugares onde os monitores estavam instalados ao centro de distribuiçāo localizado no setor de produçāo audiovisual. Esse sistema facilitou a ampla utilizaçāo dos videos, no correr dos anos, pelos alunos e professores do CCS.

$\mathrm{Na}$ época, os roteiros dos vídeos e sua direção corriam por conta da própria equipe do Nutes, assessorada por especialistas de contcúdo. A direção era assumida ora pelo médico assessor, ora por outro membro da equipe, c os atores eram os próprios alunos, membros da equipe do Nutes e professores do curso de Medicina. A vinculaçāo do Nutes ao Centro LatinoAmericano de Tecnologia Educacional (Clates) proporcionava ampla divulgação e distribuiçāo dos materiais instrucionais produzidos entre os paises latino-americanos, a partir de convênios firnıados principalmente com a Organizaçāo PanAmericana de Saúde (OPS), dentro de sua politica de transferência de conhecimentos e experiências para professores de outras universidades.

Ainda com o objetivo de contribuir para o preparo pedagógico de docentes, o Nutes passa a desenvolver modelos que utilizam a estratégia de aprendizagem para o domínio, para o treinamento didático de professores do Instituto de Ciências Básicas da UFRJ, conforme descrito por I"ontanive 2 . Esses modelos foram posteriormente ampliados para o treinamento de professores em geral, como programas de extensāo universitária.

A partir de 1974, o Nutes obtém know-hơve passa a utilizar a tecnologia de treinamento em larga escala, que se fundamenta principalmente na análise experimental do comportamento, para desenvolver vários projetos regionais pałra a América Latina, patrocinados pela OPS, envolvendo a produçāo de módulos instrucionais além de treinamento de pessoal em nivel de gcrência de recursos humanos. Entre esses projetos, merece destaque o de Tecnologia Educacional para a Enfermagem, que proporcionou a implantaçāo de dez subcentros distribuidos por sete paises da América Latina. Constitui também atividade prioritária do Nutes, na década de 70, a assessoria para implantaçāo de modelo de au to-instruçāo no ciclo básico. Assim é que, em 1976, todos os alunos do segundo e terceiro semestres do ciclo básico eram submetidos à auto-instruçāo. Outra atividade do núcleona época era o desenvol vimento de sofłunre qque possibilitasse o uso do computador como condjuvante na aprendizagem (Computer Assisted Instruction - CAI) e a 
avaliaçāo formativa dos alunos, a partir de programas que utilizavam a linguagem Mumps. Para se ter idéia da abrangência desse trabalho, cm 1977 o Nutes colocava 13 terminais de computador, 12 horas por dia, à disposição dos 617 alunos do CCS. Houve transferència dessa tecnologia para várias instituiçōes educacionais na América Latina, a última tendo ocorrido cm 1985, em projetos de cooperação técnica com Cuba. Deve-se notar que tanto os cursos de treinamento quanto os materiais desenvolvidos nessa época têm por base modelos instrucionais norte-americanos. Por excmplo, o modelo auto-instrucional introduzido no ciclo básico do CCS foi baseado na experiência da OhioState University of Medicine. E, no decorrer da década de 80 , o Nutes realizou a dublagem de inúmeros videos educacionais norte-americanos, que passaram a ser utilizados no ciclo básico do CCS.

Nảo se pode entender o trabalho do Nutes na época e sua produçāo de videos sem se voltar aos fundamentos que norteavam as iniciativas que, no inicio dos anos 70, dirigiam-se ao desenvolvimento da Tecnologia Educacional no Brasil. E incontestável a influéncia do pensamento positivista nas práticas educacionais entāo prevalentes. Esse paradigma apresenta uma visāo tecnocrática do conhecimento e da ciência, uma vez que, como sustentado por Giroux ${ }^{4}$, destaca a ciência da questāo dos fins e da ética, apresenta os fatos desvinculados dos valores, coloca a objetividade como critério que solapa a critica. O modelo das ciências naturais, transposto para a educação, resulta em sua "cientifização": critérios de controle, generalizaçāo, eficiència e produtividade adquirem status de fins. Estes critérios se coadunam perfeitamente na concepçāo científica da educação encarmada pelo modelo de Tecnologia Educacional que chega ao Brasil, importado dos Estados Unidos, nos anos 60: o controle das condiçoes doensinu é lujuertrufiádo por meio da ênfase no planejamento sistêmico e no uso de recursos instrucionais. Assim, entende-se Tecnologia como uma forma sistemática de planejar, implementar e avaliar o processo educativo, incorporando ao mesmo recursos tecnológicos Trata-se de tornar mais eficientes as experiências educativas e de difundi-las a um maior número de pessoas, reduzindo os gastos. Os meios tecnológicos, assim como o planejamento racional da educação, constituem os recursos pretensamente neutros util izados para cste fim, embasados nos conhecimentos da psicologia experimental, da teoria de sistemas e de com unicaçāo, desvinculados das circunstâncias históricas que os produziram, sem atingir os problemas essenciais da educação.
Os videos produzidos nesse periodo voltam-se basicamente à transmissāo de conceitos (em anatomia, fisiologia, histologia, etc.), dentro de uma perspectiva de objetividade dos fatos, excluindo quaisquer questōes de ordem ética ou valora tiva, como em video no qual crianças são usadas num experimento longitudinal, exibidas como se fossem objetos. Há ainda os audiovisuais que têm por objetivo o desenvolvinueılu de habilidades téenicas, mostrnndo de forma linear "como fazer", sendo exemplos do "modelo bancário" da educaçāo, assim chamado por Freire" (1973): concebe-se o cérebro do aprendiz como um recipiente vazio, mero depósito de conhecimentos transmitidos de forma nāo-problematizada por aquele que detém o conhecimento. A tōnica dos videos produzidos na época é coerente também com o modelo flexneriano prevalente na formaçāo e prática médica, em que a cura se sobrepōe à prevençāo, o individual ao coletivo, o biológico é desvinculado das indeterminaçōes sociais, politicas e culturais.

Nāo resta dúvida de que o modelo "neutro" e universal não se manifesta apenas nas práticas entảo prevalentes no Nutes, mas permeia, ora mais ora menos acentuadamente, as teorias e práticas prevalentes no contexto educacional brasileiro. Naturalmente, esse modelo nảo se manifesta de forma monolítica, havendo também, no caso do trabalho entāo desenvolvido no núcleo, posturas mais progressistas, que se manifestam em algumas práticas de assessoria, de planejamento e execução de aulas, de produçāo de materiais educativos. Entretanto, tais posturas nāo ganharam visibilidade, sendo possivel identificar o tecnicismo - entendido como a aplicaçāo de modelos que hipertrofiam o lugar da técnica no campo pedagégico - como o modelo prevalente na época. Trata-se de uma ¿́poca marcado pelo rcgime de excę̧ües, que, mesmo quando cede lugar à transiçāo democrática, deixa marcas que têm reflexos nas concepçōes teóricas e nas práticas das instituiçōes escolares. Esse modelo, ao despolitizar a cducaçāo, excluindo da pauta as inf́luências dos determinantes sócioeconômico-politicos, é funcional para a manutençāodo sistema político, com restrição às liberdades democráticas, que desde 1964 imperava no P'aís. Pode-se dizer que, de maneira geral, a atua çāo do Nutes não constituiu, na época, espaço de resistência importante à ordem estabelecida.

O reconhecimento do papel ampliado do profissional de saúde, incluindo sua capacidade de se relacionar com o cliente, se evidencia em alguınas produçðes do Nutes a partir da segunda metade da década de 70 . Nessas produçōes, resgata- 
se como parte das preocupaçōes da atenção médica a subjetividade do homem, encarnada num profissional da saúde que expressa c reconhece sentimentos. Trata-se de romper com a divisão estabelecida entre o físico e o emocional, com contornos tāo nitidos e ainda hoje prevalentes na formaçāo e nas práticas de saúde. Deve-se lembrar que, ainda na década de 70, chega ao Brasil uma forte influĉncia da abordagem humanista nos meios educacionais, que se faz sentir, por exemplo, no psicológico incorporado ao conceito saúde/ doença . Sob a influência dos movimentos de medicina integral e conuunitária, inicia-se também, na época, a produção de videos de caráter preventivo, mas a realidade ainda é vista de forma fragmentada, uma vez que as determinaçōes económico-sociais nāo são contempladas.

\section{ANOS 80: NOVAS BASES CONCEITUAIS}

No inicio dos anos 80, alguns acontecimentos exercem influćncia importante nas orientaçōes do Nutes. Em 1980, o nucleo atravessa série crise financeira, reflexo cm grande parte da crise económica do Pais, o que acarreta, inclusive, a detcrioraçāo de suas instalaçōes. Além disso, em 1981, scu diretor-fundador pedc exoneraçāo e cm 1983 ocorre o término do Clates na UFR]. A atuaçāo do Nutes na América Latina, principalmente por meio de cursos de treinamento, diminui consideravelmente. Suas atividades docentes afastam-se cada vez mais da extensāo c concentram-se nos cursos de Pedagogia Médica e Didática Especial, que jả vinham sendo ministrados, desde 1979, para mestrandos do Centro de Ciências da Saúde, bem como no curso de especializaçāo de Educaçāo na área de Sa úde, que, a partir de 1980, o Nutes passa a oferecer anualmente a profissionais de saude. A assessoria a docentes do $C C S$, que jả vinha diminuindo no final dos anos 70 , perde importíncia em seu trabalho.

Conforme exposto por Souza", é na década de 80 que, aos poucos, a crítica a uma visāo reducionista da Tecnologia Educacional, que afirma a autonomia da dimensāo técnica do ensino, se instala no Nutes, que procura redefinir sua identidade. Esse questionamento é parte de um movimento maior. incluindo a critica aos modelos importados, que se instala no País no fim dos anos 70 à medida que acontece a abertura politica. $A$ influência dos teóricos neomarxistas se faz sentir, revestindo de um cunho político certas concepçōes e práticas educativas: a escola passa a ser vista como "aparelho reprodutor da ideologia dominante", e ganha hegemonia a seguir a posição histórico-crítica ${ }^{6}$.
$A$ incorporação de propostas de reforma do sistema de saúde e educacional, como Integraçāo Docente Assistencial (IDA) e Açōes Integradas de Saúde (AIS), às atividades do núcleo, principalmente por meio dos projetos de treinamento que, a partir de 1983, o núclco desenvolve para o Programa de Aperfeiçoamento de Pessoal na área de Saúde (PAPPS), com certeza também influi para que reflexōes sobre a politica da Reforma Sanitária perpassem seu trabalho. Isto nāo significa, entretanto, que a partir dai o Nutes incorpore ao seu trabalho uma linha de atuação consistentemente critica, comprometida com transformaçỏes sociais. Em primeiro lugar, deve-se lembrar que tais mudanças pressupōem modificaçỏes cm valores e na própria concepção que se tem do conhecimento, o que é dificultado, entre outros fatores, pelo forte enraizamento em bases positivistas do trabalho do Nutes. Encontrar espaço para um trabalho comprometido no sistema capitalista em que se atua pressupōe que o núcleo possua clareza em seu posicionamento ideológico e que consiga se engajar em projetos que, ao menos, nāo scjam antagônicos às suas orientaçōes. Ao se analisar o tipo de atividade desenvolvida pelo Nutes, é importante lembrar que, em sua história, conforme lembrado por Sigaud ${ }^{7}$, muitas vezes o núcleo teve que trabalhar em projetos alheios a seus objetivos, devido a sua dependência de recursos externos para financiamento. É o caso dos treinamentos que ministrou em 1979, em convênio com o entāo Instituto Nacional de Medicina e Previdência Social (Inamps), para pessoal de primeiro e segundo graus, dos 30 módulos instrucionais que desenvolveu em 1983 para capacitaçāo de recursos humanos da Companhia de Águas e Esgotos do Rio Crande do Norte (Caern) e de vários conjuntos de eslaidessom produzidos em 1985 para treinamento de operadores de sistemas de abastecimento de água.

Um importante espaço que o Nutes vem ganhando nos últimos anos referc-se à natureza de sua inserção em projetos. Em sua origem, cocrentemente com a descontextuali»ação política e social vigente nas práticas educativas, o núcleo, na maioria dos casos, contribuia com a técnica para viabilizar idéias desenvolvidas por outros: individualizava o ensino, "trcinava" docentes, desenvolvia videos paia o ciclo básicu clu CCS. Atualmente, tenta-se reverter esse quadro, jå que se tem como preocupaçāo central participar em definiçỏes importantes dos projetos, desde a fase de sua concepçāo, e imprimir aos mesmos uma visão de educação e saúde norteada pelos principios de equiidade e transformaçāo social. O núcleo busca, hoje, um entendimento mais amplo da problemática educacional e de 
saúde, em que determinantes sociais, politicos e econômicos ocupam papel central, e é esta a perspectiva que orienta sua participaçāo atual em projetos. $\wedge$ dualidade teoria/prática que perpassa as experiências educacionais - a qual na área de saúdc ć refletida também no distanciamento ensino/trabalho - , bem como a dicotomia que se vem tradicionalmente estabelecendo entre prevençāo/cura ocupam lugar privilegiado nas reflexōes da equipc, o que já se tenta traduzir em sua atividade docentc, em sua participação $\mathrm{cm}$ projetos $\mathrm{c} \mathrm{cm}$ sua produção de materiais. E, o que é muito importantc, cada vez mais se configura em seu trabalho um processo de autocritica e se criam condiçōes para fazer da avaliaçāo um componente de seu trabalho, o que se percebc como essencial para que se engaje no processo de criaçāo de conhecimentos, cuja referência passa a ser a realidade nacional.

$\Lambda$ produção de vídeos mais uma vez é espelho dessa orientaçño modificada. Pode-se dizer que o objetivo principal desses vídeos é a conscientização dos profissionais de saúde para o entendimento dos determinantes de seu trabalho, scja no atendimento à populaçāo, seja como docentes, e ao mesmo tempo para o potencial que thes é dado, nestas funçōes, dc transformar a realidade. Ganha papel central o homem, que sofre determinaçōes sociais múltiplas e influi em mudanças de uma realidade que é vista como multidimensional e complexa, com aspectos que agem uns sobre os outros em forma de contraposição e conflito. $O$ conccito de saúde/doença, nessa perspectiva, é modificado, passando a ser entendido como resultante também de condiçōes de vida, conforme definiçāo da VIIl Conferência Nacional de Saúde.

A realidade complexa e conflituosa do sistema de saúde é constituída a partir da voz que se dá aos diversos grupos que, de uma forma ou de outra, se relacionam no sistema: assim é que são privilegiados depoimentos de pacientes sobre o atendimento que recebem, bem como da equipe de saúde e de responsáveis pela politica e administ raçāo do sistema. Em alguns desses vídeos, os argumentos são construidos a partir unicamente de depoimentos, enquanto em outros a ficçāo é utilizada para veicular as mensagens, às vezes com depoimentos intercalando o enredo. Elementos de contradição e de transformação perpassam a estrutura e o conteúdo desses materiais. Conhecimentos básicos sobre os problemas de saúde abordados também são desenvolvidos, ocupando, entretanto, papel secundário em relação ao objetivo maior de sensibilização. Alguns desses videos foram realizados dentro de um Programa de Integração Ensino-Serviço, a partir de
1987, nas áreas de tuberculose, hanseníase, câncer e hipertensão arterial, $\mathrm{cm}$ convênio com o Ministério da Saúde. Livros-texto e conjuntos de eslaides-som também foram desenvolvidos nesse programa, num processo de trabalho coletivo, tendo em vista contribuir para a melhoria do ensino dessas patologias nos cursos de graduaçāo $\mathrm{cm}$ Medicina, todos tendo como eixo a integração ensino-trabalho. Nessa mesma linha, foi produzido em 1988 um video, em convênio com o lnamps, dentro do projetode $\Lambda$ ssistência Pcrinatal, que retrata a situaçāo do atendimento a gestantes a partir de diversos depoimentos. Um programa de video, com mensagem também muito forte, produzido em 1986 e que retrata a visāo ampliada do Nutes sobre os problemas de saúde c educaçāo, diz. respcito à questāo da reforma agrária.

Por serem materiais que problematizam a realidade, deixando questōes importantes em aberto, e por sc reconhecer que os fatos e elementos críticos neles contidos necessitam ser interpretados, considera-sc essencial que discussōes sigam sua apresentaçāo. A desestabilizaçāo da audiência - profissionais da saúde/alunos de mestrado, profissionais da saúde/docentes universitários - frente à apresentaçāo dos vídeos, com o respectivo "acordar" para a problemática maior do sistema de saúde, constitui indicio de que um dos objetivos principais desses videos vem sendo cumprido, à medida que se criam espaços para mudanças dentro dos condicionamentos do sistema.

\section{CONCLUSĀO}

O resgate da história da Tecnologia Educacional voltada à área de saúde no Brasil passa necessariamente pelo conhecimento do trabalho do Nutes, dado o pioneirismo desse núcleo na área e o espaço que ocupou no decorrer dos anos. Esse fato, acrescido da grande demanda dos materiais que o núcleo tem produzido e dos inumeros cursos que $t \mathrm{~cm}$ ministrado voltados à formação de profissionais da saúdc, atesta a importância de proceder a uma análise cuidadosa de todo o trabalho realizado pelo Nutes.

Eindiscutivel a importância do know-how técnico desenvolvido pelo núcleo ao longo dos anos, por meio do empenho e competência das diferentes administraçōes e corpo docente-técnico-administrativo. É a solidez desta base que abre caminho para que hoje o núcleo possa perseguir o aperfeiçoamento da técnica inserido num questionamento constante sobre a finalidade social e politica dos processos de 
planejamento, de produção de materiais, etc. em que sc engaja. Trata-se, em outras palavras, de pensar e agir dentro de uma concepção de Tecnologia Educacional - processos e produtos identificada sempre com a indagação dos fins que se quer atingir, levando-se em conta, como exposto por Candau', a relevància de seu trabalho para a construção da humanidade.

O equilibrio almejado em contraposiçāo à hipertrofia da dimensāo metodológica na teoria c prática educativas pressupóe o desenvolvimento dos conteúdos de forma contextualizada c critica, com as técnicas utilizadas a serviço desta proposta. A integraçño dos três componentes-conteúdo, técnica e contextualização política - passa a ser um desafio, dentro de um processo contínuo de auto-rcflexão e produçĩo de conhecimentos.

O desenvolvimento de pesquisas na área de Tecnologia Educacional $\mathrm{cm}$ Saúde é, sem dúvida, um caminho necessário para alcançar tal propósito. No caso do video educativo, reconhece-se a importância de uma investigação mais sistemática, sempre articulada com o reconhecimento de suas influências políticas, cconômicas e sociais. Dentre as questōes que já vêm sendo investigadas no núclco, inseridas na área de Tecnologia Educacional que integra o programa de mestrado em Educaçāo em Saúde recém-criado no Nutes, destacam-se: Comose constrói a intenção pedagógica dos videos educativos? Que propostas de educaçño c saúde estāo por trás das mensagens veiculadas? O que é na verdade apreendido pela clientela a que se destinam? Como se dão as mediaçōes feitas pelos professores e educandos no uso do recurso? Como se articulam as intençōes pedagógicas e a expressāo estética do video?

Em outras palavras, considera-se que o Nutes hoje tem condiçōes para se engajar num processo de produçāo de conhecimentos e de autocritica que venlıa a contribuir na consolidação de um projeto mais critico da educação em saúde, no qual a Tecnologia Educacional dê sua contribuição no sentido de legitimar uma educação brasileira contextualizada e comprometida com transformaçōes sociais.

\section{SUMMARY}

Based on a historical review of Niutes/CCS/UFR/ educational vidco production, and of its connection with the major educational trends and the langer social context, this artick attcmpts to identify the underlying ideologies of this educational techmology center throughout its' 25 years of existence.
KI:Y IKC)RDS

- liducational vitien;

- liducational icchrolugn:

- I:ducation in health.

\section{AGRADECIMENTO}

A autora agradece aos colegas do Nutes as sugestōes sobre o texto.

\section{REFEREANCIAS BIBLIOGRÁFICAS}

1. CANDAU, V. Tecnologia Educacional e mudança social. Mimeo. UI:RJ/RJ, 1980.

2.. ГONTANIVE, N. Modelo de Aprendizagem para o domínio de Benjamim Bloom. Uma experiência de utilização. Tecnologia Educacional, Associaçāo Brasileira de Tecnologia Educacional - ABT, julho/ago 1980, n²35.

3. FREJRE, P. Extensāo ou Comunicação? Rio de Janeiro, Paze Terra, 1973.

4. GIROUX, H. Teoria crítica e resistência em educação. Petrópolis, Vozes, 1983.

5. LOBO, L. C. G. Implantação do Núcleo de Tecnologia Educacional para a Saúde e do Centro Latino Americano de Tecnologia Educacional para a Saúde. Rio de Janeiro, 1970 (mimeo).

6. SEVERINO, A. J. Educaçāo, idcologia e contra-ideologia. Sāo Paulo: EPU, 1986.

7. SIGAUD, M. A. Educactional Technology in Brazil. A transactional analysis of Nutes/Clates (mimeo, 1980).

8. SIGAUD, M. A. O ensino no ciclo básico. Uma abordagem integrada. Trabalho apresentado no XVI Congresso Brasileiro de Fisiologia de Sociedade Brasileira de Fisiologia, realizado no Rio de Janeiro, de 4 a 7 de abril de 1982

9. SOUZA, A. A. Tecnologia Educacional na área da Saúde. Tecnologia Educacional, ABT., ano XII n²4, set-out 1983. 